Ethiopian Journal of Environmental Studies \& Management 9(6): 666 - 679, 2016.

ISSN:1998-0507

doi: http://dx.doi.org/10.4314/ejesm.v9i6.1

Submitted: December 14, 2015

Accepted: October 31, 2016

\title{
ASSESSMENT OF SOLID WASTE MANAGEMENT SYSTEMS IN IBADAN NORTH, OYO STATE USING GEO-SPATIAL TECHNIQUES
}

\section{POPOOLA, A.A., 1 *AYANGBILE, 0.A. ${ }^{1}$ AND ADELEYE, B.M. ${ }^{2}$}

${ }^{1}$ Department of Urban and Regional Planning, University of Ibadan, Oyo State, Nigeria

${ }^{2}$ Department of Urban and Regional Planning, Federal University of Technology, Minna, Niger State, Nigeria

\begin{abstract}
Solid waste management has been part of human activities right from time. Effort by the Oyo State Government in managing the collection and disposal of waste generated in Ibadan is seen in the provision of Skip bins at specific locations across the city. However, despite the provisions made by the government, an emerging trend is the dumping of refuse along the median of some major and collector roads in the city. This study aims at emphasizing a planning framework for the location of solid waste disposal infrastructure (Skip bins) through the adoption of planning standard. The aim of this study was achieved by identifying the existing skip bins within Ibadan North. More so, a spatial analysis of skip bins and resident's access to solid waste facilities within Ibadan North was deduced. Geospatial techniques were used for this study; data from primary and secondary source were also used to corroborate the geospatial findings. The study identified a total of 37 skip bins located within Ibadan North Local Government, serving the entire Ibadan North. Spatial analysis of the skip bins revealed a clustered distribution which is consequential to indiscriminate solid waste disposal within Ibadan North. The study recommends adequate provision and location of skip bins to contribute to a cleaner and safer environment and a design blue print for Ibadan North was proposed.
\end{abstract}

Key Words: GIS, Median, Nearest Neighbour Analysis (NNA), Skip Bins

\section{Introduction}

Solid wastes constitute a growing problem and have gained increased political awareness over recent years (Amuda et al., 2014).The amount of solid waste generated in the world is steadily increasing and every government in the world is currently focusing on methods to approach the challenges posed by municipal solid waste management (Schwarz-Herionet al., 2008). The increase in population as a result of industrial revolution in major towns and cities of the world have necessitated rapid growth or high rate of urbanization and development, for instance, Nigeria cities in recent time have witnessed rapid population growth resulting from influx

*Corresponding Author: Ayanbgile, O.A.

Email: bukiayangbile@yahoo.com 
Assessment of Solid Waste Management Systems in Ibadan North................POPOOLA et al.

of migrants from rural area to the cities (Adejobi and Olorunnimbe, 2012).

Waste is a wide ranging term encompassing most unwanted materials, defined by the Environmental Protection Act 1990. Wastes are 'those substances or objects which fall out of the commercial cycle or chain of utility'. World Health Organization (2008) defined waste as "something, which the owner no longer wants at a given time and place and which has no current or perceived market value".

Solid waste management is the application of techniques that will ensure the orderly execution of the functions of collection, transfer, processing, treatment and disposal waste (Onu et al., 2012). The ever increasing global concern on environmental health demands that waste be properly managed in the most friendly and acceptable way. This is to minimize, and where possible, eliminate its potential harm to humans, plants, animals and natural resources. Hence, the challenge of solid waste management has been a growing concern for government, environmentalist and communities at large, thus preoccupying the urban man. Effort by the Oyo State Government in managing the collection and disposal of solid waste generated in Ibadan is seen in the provision of Skip bins at specific locations across the city. However, despite the provisions made by the government, piles of solid waste are often found by roads and many other open spaces in the cities.

Ogwuche (2013) in his study conducted on Bauchi, Nigeria succeeded in showing the efficiency of GIS technology in waste management in a complex urban setting, heightened by the forces of urbanization, increase in population, and increasing socioeconomic activities. From the result of his study, the integrated solid waste management is recommended if sustainable solid waste management in urban areas is to be achieved; and to facilitate this requires the adoption of GIS technology for acquisition, processing, storage and presentation of geospatial information.

Mundhe et al. (2014) in their study on Pune city also demonstrated that the capacity to use GIS, GPS and remote sensing technology for the effective assessment of solid waste management system will minimize the environmental risk and human health problems.

Concurrently, Shah and Wani 2014 in their study on Waste Disposal asserted that the socio-economic and environmental problems associated with the solid disposal site are complex because of the quantity and diverse nature of the wastes. Therefore, solid waste should be managed by modern technologies and methods that support long term sustainability of communities and environment. Their study employed integrated methodology through Geographic Information System (GIS) for the selection of sites that are suitable for the disposal of solid waste. This methodology incorporates a large number of environmental and socio-economic parameters which are essential to identify the sites which have minimum adverse impact on environment. Hence, this study also adopts the use of Geo-spatial techniques in assessing solid waste management systems in Ibadan, Nigeria.

\section{Problem and Objectives}

Waste management is a visible urban service and thus serves as a good indicator of performance of a 
municipality or government. Its effectiveness and sustainability serves as an indicator for good local governance, sound municipal management and successful urban reforms.

Despite waste management being considered as a necessity and integral to city liveability, urban and environmental managers in Nigeria have not been able to provide a workable, sustainable and permanent solution to the indiscriminate disposal of refuse within the urban corridors. Median dumping of refuse is one improper method of solid waste disposal that just emerged in the city of Ibadan. This act of lackadaisical means of disposing refuse has left the road divide stinking with odors from decayed sediments and waste materials which have been left for a long period of time. Thus, city corridors are now breeding places for rodents, insects and diseases. Inadequate distribution of refuse bin makes it impossible to establish the reason behind the indiscriminate disposal of refuse along the road divide.

This study presents an analysis of the major solid waste disposal infrastructures (Skip bins) in place within the study area and the new trend of median dumping which can be attributed to certain factors. The study aims at providing a planning framework for the location of solid wastedisposal infrastructures (Skip bins) through the adoption of the planning standard. Its specific objectives are to map out the spatial distribution of skip bins location within the area of study; to identify routes characterized by median dumping of refuse, to identify the factors influencing dumping of refuse along road medians; to determine the average travel distance of residents to skip bins location and to propose new skip bins location within the study area.

The objectives of the study include:

i. To identify the existing skip bins and points of waste disposal within Ibadan North;

ii. To provide a spatial analysis of the existing solid waste Facilities (Skip Bins) within Ibadan North;

iii. To appraise resident's access to waste facilities within Ibadan North;

iv. To provide a design blue print to ameliorate the problem of indiscriminate waste in Ibadan North.

\section{Study Area}

The Ibadan North Local Government is located within $3^{\circ} 59^{\prime}$ East longitude and $7^{\circ} 20^{\prime}$ North Latitude. The total land area is about $2633199 \mathrm{~m}^{2}$ with a population of about 306,795 at the 2006 census (NIPOST, 2009). The local government area is a metropolitan community and it is the most populated in the state (Official website, Oyo State Government, 2014).It is predominantly a home for small, medium, and large scale commercial activities and also serves as the center for most commercial organization headquarters, such as bank and the State Secretariat among others. The Local Government area is a host to many educational centers in Nigeria including the University of Ibadan, the University College Hospital (UCH), the Polytechnic Ibadan, National Horticultural Research Institute (NIHORT) and the Nigerian Institute of Social and Economic Research (NISER). The most notable mode of transport in the study area is road transport, the rail line however cut across the local government from Sango to Bodija and also hosts the former Ibadan Local Airport. 


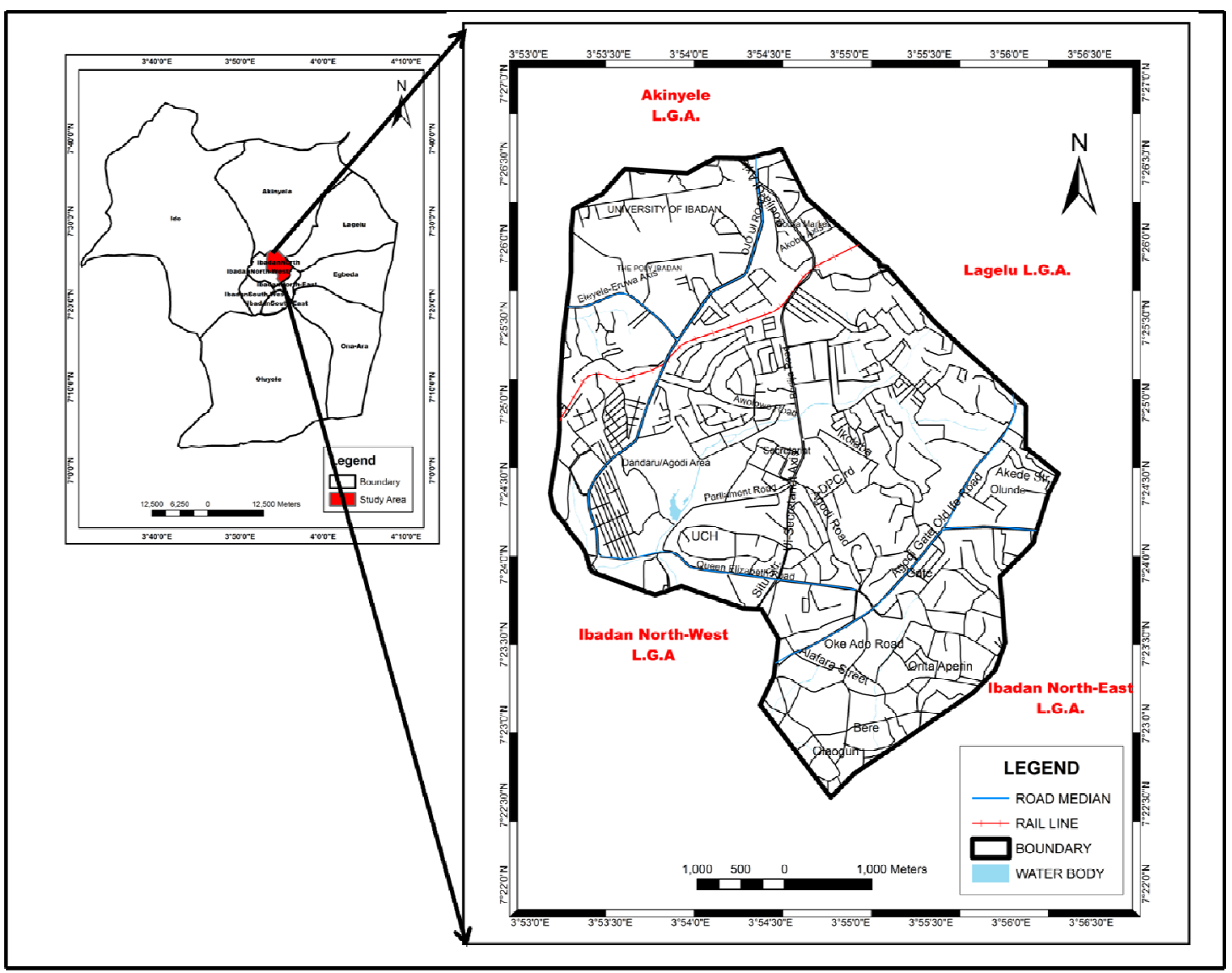

Figure 1: Scaled Map of the Study area cut out of the Ibadan Map

\section{Methodology}

Data for this study was sourced from the primary and the secondary sources. The primary sources of data include the acquisition of the an Ikonos image of the study area, ground truthing, picking of skip bins coordinates within the study area and questionnaire administration while the secondary sources of data include information from internet, journals relevant to the study and the acquisition of the administrative map of the study area from the state ministry of Survey.

\section{Geospatial Techniques and Post Processing}

Geospatial based techniques were used in the research. In the first phase, an
"Ikonos" image of 1 meter and 4 meters panchromatic and multispectral visible bands respectively was obtained. The administrative map of the study was scanned and the raster image was imported to Arc-GIS10.2, the Raster image was geo-referenced and the boundary of the said map was digitized. The boundary shape file for the study area digitized was over laid on the "Ikonos" image and the area of interest (Ibadan North) was "Sub-set" thus the extent of the study area was determined. An on screen digitization of features (road network, road medians and water bodies) was done on the "sub-set" image of Ibadan North using Arc-GIS 10.2. Coordinates $(\mathrm{X}, \mathrm{Y})$ of skip bins within 
the study area that were picked, were recorded on excel sheets and these coordinates were later imported into ArcGIS 10.2 software environment. The spatial location of the refuse dump along road medians and locations of skip bins within the study area were displayed on the image. To ascertain the spatial distribution of skip bins, distances between each point of the skip bins and the closet point to these skip bins, a Near Neighbour Analysis was carried out at the Second Phase of the post processing. This task was achieved by subjecting the coordinates $(\mathrm{X}, \mathrm{Y})$ that were picked to the "Analyzing pattern" tool found under the "Spatial Statistics" tools of Arc-GIS 10.2 software. An analysis pattern of Average Nearest Neighbour was selected with an Euclidean distance which is found under the "Spatial Statistics Tools" on Arc-GIS 10.2 software.

The Average Nearest Neighbour tool on Arc-GIS 10.2 software measures the distance between each feature centroid and its Nearest Neighbour centroid location. The Average Nearest Neighbour tool also gives the average distances of all the centroid locations. Whenever the average distance is less than the average for a hypothetical random distribution, the distribution of the features being analyzed is considered clustered. In a situation where by the average distance is greater than a hypothetical random distribution, the features are considered dispersed. The average nearest Neighbour ratio is calculated as the observed average distance divided by the expected average distance (GISC, 2014).
At the third phase of the post processing three maps were produced showing the spatial distribution of the skip bins, the refuse dump points on median within the study area and the map showing the proposed skip bins within the study area. All these maps were embellished on the layout view of ArcGIS 10.2 software.

\section{Data Processing Techniques}

The data processing techniques used for this research include: Display of coordinates, Data Sub-setting, Georeferencing and Average Nearest Neighbour.

\section{Field Survey}

Field survey was corroborated with the geospatial analysis so as to have an adequate conclusion and recommendation. A total number of 50 questionnaires were administered within the study area covering the major areas where refuse are being dumped along the median. These includes Ojoo, University of Ibadan, Sango and Mokola area, Iwo Road, Gate and Roundabout area, SangoEleyele area, Bodija and Beere area, Ashi-Bodija area, Ikolaba area and UIAgbowo express area. Simple random sampling method was used to select interviewees. Global Position System and Camera were used in picking coordinates and taking photographs on site respectively. Respondents were selected along the road corridors which comprises of residential building and commercial building. The sampling was done along various corridor of different travel axis (table 1). 
Table 1: Sampling procedure among neigbourhoods along various travel axis

\begin{tabular}{lll}
\hline S/N & Respondents travel axis & Ne \\
\hline 1 & Iwo Road- Gate-Roundabout- & Be \\
& Beere- Mokola Axis \\
2 & UI- Bodija- Secretariat-Beere Axis & Bo \\
3 & Ojoo-UI-Sango-Mokola Axis & Un \\
4 & Sango- Eleyele Axis & Oro \\
4 & Ele \\
Results and Discussion & \\
Solid Waste disposal/Existing \\
Infrastructure in Ibadan North Local \\
Government
\end{tabular}

A total of 37 skip bins were identified during the course of the study. Of the respondents, $66 \%$ see dumping of solid waste along road medians as a reflection of government's insufficient provision of skip bins at required locations while the remaining 34\% consider it as a reflection of peoples' dirty habit and also opined the notion that government solid waste collectors frown at this attitude but yet unable to bypass a heap of refuse seen along the road when their rounds of waste collection is being made. Another $66 \%$ believe that the skip bins are located far from their homes/shops; only about $12 \%$ of respondents travel less than $150 \mathrm{~m}$ to the nearest skip bin, $18 \%$ travel between $150 \mathrm{~m}$ to $250 \mathrm{~m}, 58 \%$ travel over $250 \mathrm{~m}$ to the nearest skip bin while $12 \%$ do not have any skip bin location within their reach. Also, the study revealed that the rate at which skip bins in different locations get full vary from less than a day (36\%), to a day (38\%) to two days or more $(26 \%)$ and this is mainly based on the population the skip bin serves as well as the frequency of collection by the State Waste Management Board. For example, skip bins in the densely populated areas of the study area like Agbowo and the
Neighbourhoods/communities

Beere, Agodi GRA, No. of respondents 12

Bodija, Ikolaba, Secretariat, UCH 15

University of Ibadan, Agbowo, 10 Orogun Ibadan, Mokola Eleyele, Ijokodo 13 market areas often get full in half a day or a day. Waste are collected on Mondays and Thursdays by the Board but sometimes, collection is delayed and so, skip bins overflow and waste covers a major part of the road. when collection is however made after the delay, skip bins gets full again in a short while due to the refuse that have been set aside in days to be disposed when skip bin is emptied. Points of these skip bins are represented in figure 1. This figure (1) explains the Cluster distributions of these skip bins within Ibadan North, with more distribution it (Skip bins) along Sango Eleyele axis.

Transportation serves as the lungs through which other sectors of the economy breathe. The death or chaos in the transportation sector indirectly influences other sector of the economy. Transportation routes provide the accessibility to the use of facilities and infrastructures in space. The waste management is not an exemption. The median dumping of refuse is an evident fact that the transport infrastructure drives the median dumping of refuse. The perception of respondents towards the distance to waste infrastructure (skip bin) is a reflection of the importance of transportation.

The nearest neighbour analysis of the distribution pattern of the skip bin as shown in figure 2 revealed a clustered distribution. The Clustered distribution 
(figure 2) of these Skip Bins could be disposal experienced in the Study area. attributed to the indiscriminate waste

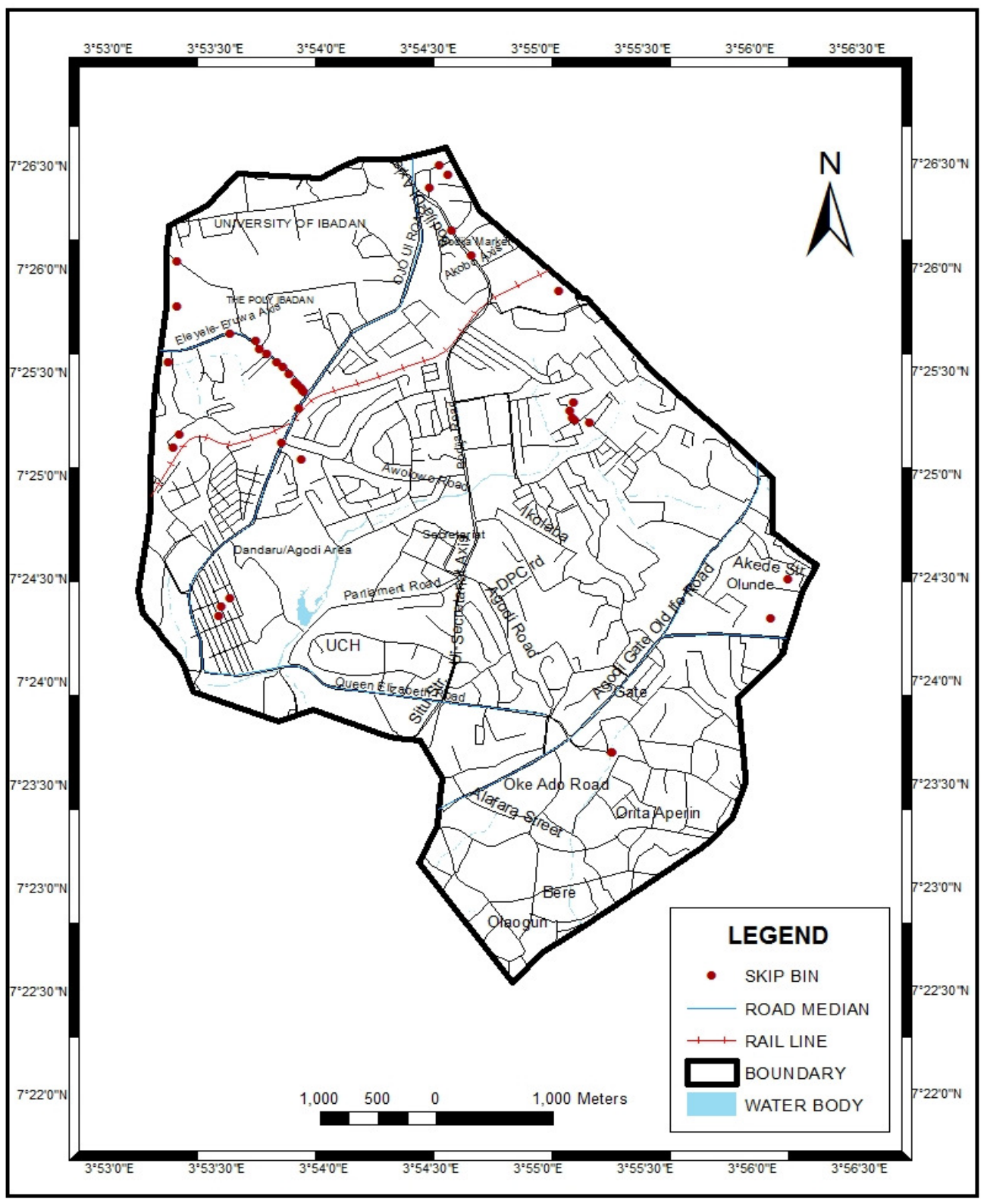

Figure 2: Spatial Distribution of Skip Bins within the Study Area

A total of 37 Skip Bins were identified within the neigbourhoods of Ibadan North; 10 of which are located along Ojoo, University of Ibadan, Sango and Mokola area, 4 located along Iwo Road, Gate and Roundabout area, 12 located along Sango-Eleyele area, 7 along University of Ibadan, Bodija and Beere area, 1 along Ashi-Bodija area, 1 in Ikolaba area and other along UI-Agbowo express area. The highest numbers of these Skip Bins are located along Sango- 
Eleyele area (12 Skip bins). 4 Skip bins are identified along Round About and Mokola Area. The least number (1) of Skip bins were located along Ashi area. These Skip Bins are located along major routes within the study area, this often occupy significant portion of the road which in turn often leads to traffic bottle neck. The study also reveals that the clustered distribution of skip bins within the study area (figure 2). With this clustered distribution of skip bins, Some areas are left with no Skip bins (Aperin,
Oke Ado, parliament road, UCH, Awolowo, Agodi) while Sango-Eleyele and University of Ibadan road has a total number of 12 and 7 Skip Bins respectively. This development often leads to indiscriminate dumping because those in the areas where skip bins are not found would be forced to travel a considerable distance before they can dispose their waste, the resultant effect of this is indiscriminate solid waste disposal.

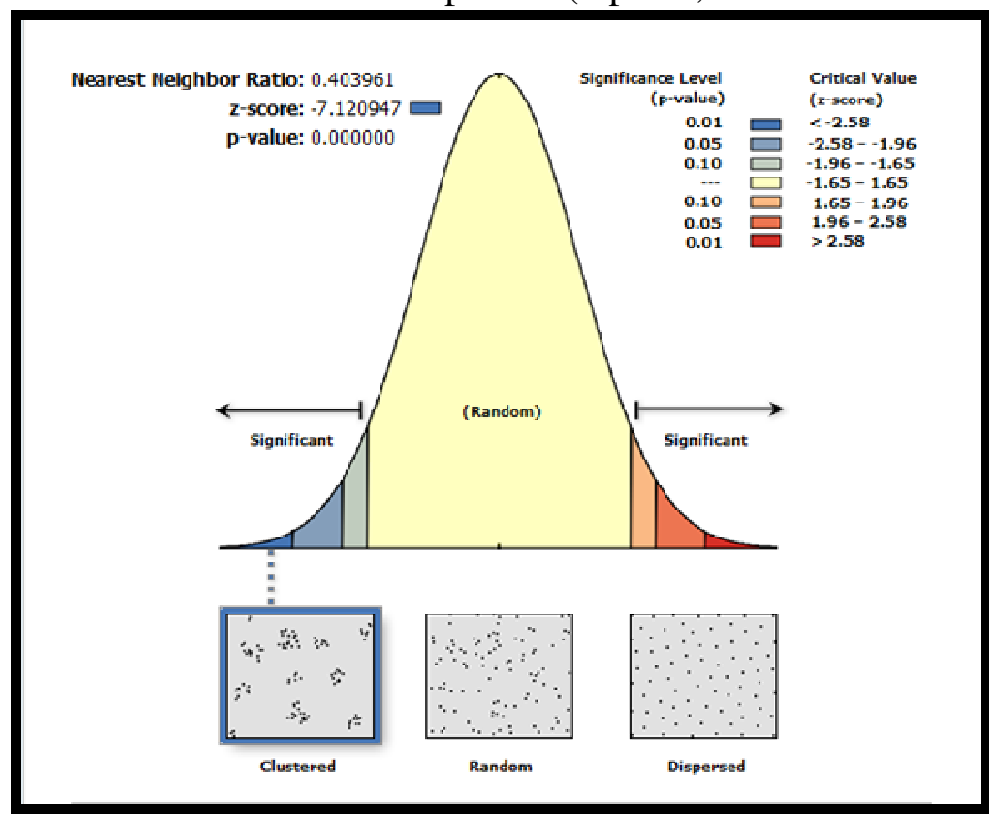

Figure 3: Average Nearest Neighbour chat for Skip Bins

From the Spatial analysis of the distribution of the skip bins carried out on Arcgis 10.2 the observed mean distance, expected mean distance, Nearest Neighbor Ratio, Z-score and the $\mathrm{P}$-Value of the average nearest neighbour were deduced (Table 1).

Table 1: Average Nearest Neighbor Summary

\begin{tabular}{ll}
\hline Observed Mean Distance: & 156.8516 Meters \\
\hline Expected Mean Distance & 388.2837 Meters \\
Nearest Neighbor Ratio & 0.403961 \\
Z-score & -7.1209 \\
p-value & 0.000000 \\
\hline
\end{tabular}


The result of the average nearest neighbour analysis also affirmed the cluster distribution of the Skip Bins within the study area (fig. 2). An Observed Mean Distance of 156.8516 Meters, Expected Mean Distance of 388.2837 meters Nearest Neighbour Ratio of 0.403961 and z-score of -7.1209 which indicate that there is a less than $1 \%$ likelihood that this could be the result of a random chance (Table 1). This result also confirmed the distribution pattern displayed in figure1. The figure 3 revealed that refuse dumped points were found along UI-Ojoo axis, UI - Bodija axis, Sango - Mokola axis, Sango Eleyele axis, Roundabout-Secretariat axis and Beere - Gate axis.

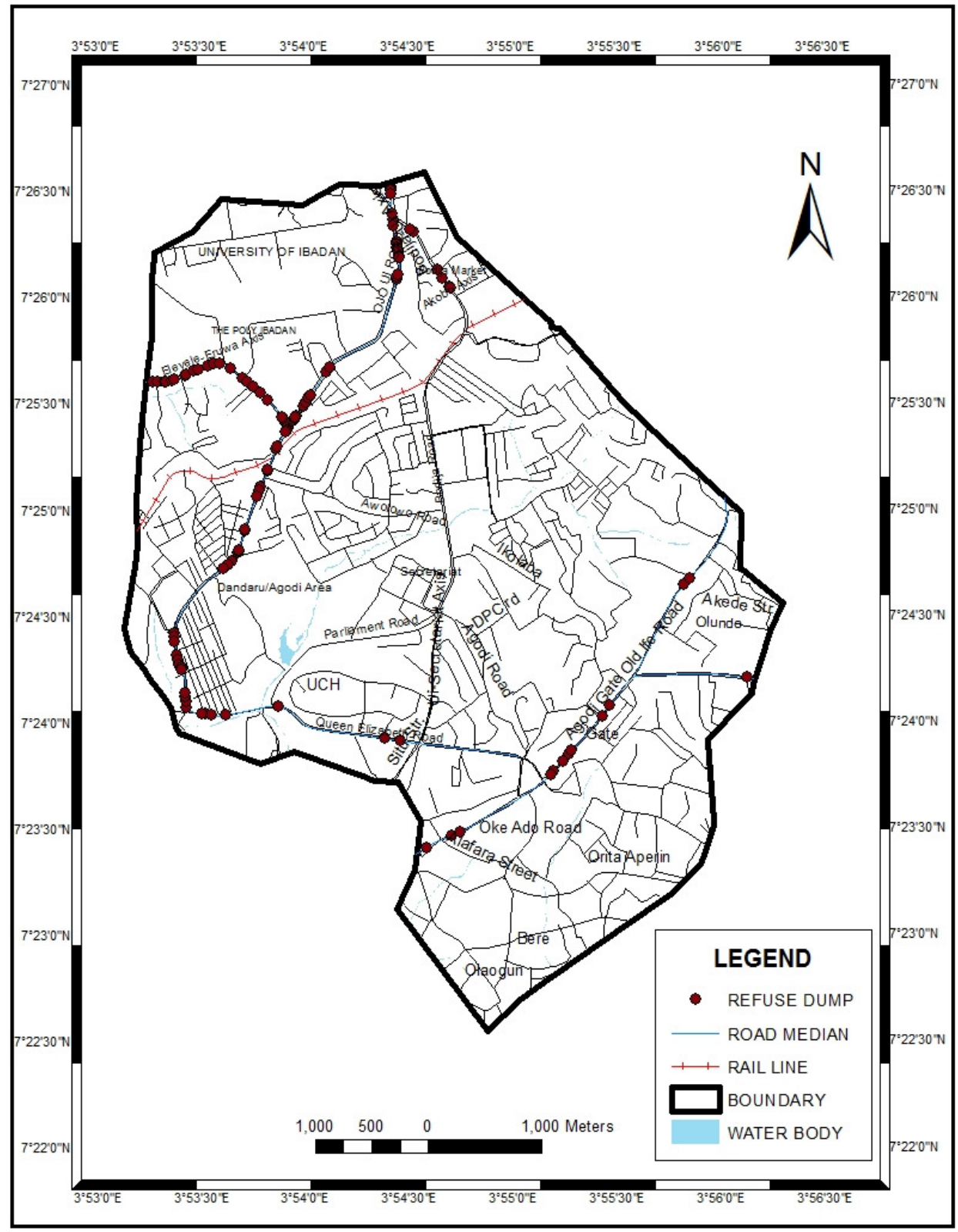

Figure 4: Refuse Dump Points on Median within the Study Area 
Table 2 reveals that Ojoo-Mokola Axis has the highest points of refuse disposal on median with 43 different points. 39, 36 and 34 different points were found along Sango-Eleyele Axis, Iwo Road-
Gate-Roundabout-UCH- Mokola Axis and UI-Bodija-Secretariat-Beere Axis respectively. Points of refuse dumped on road median are shown in figure 3 .

Table 2: Road Median Dumping

\begin{tabular}{lll}
\hline S/N & Location(median dumping of refuse) & Number of points \\
\hline 1 & Ojoo-UI-Sango-Mokola Axis & 43 \\
2 & Sango- Eleyele Axis & 39 \\
3 & Iwo Road- Gate-Roundabout- Beere- Mokola Axis & 36 \\
4 & UI- Bodija- Secretariat-Beere Axis & 34 \\
\hline
\end{tabular}

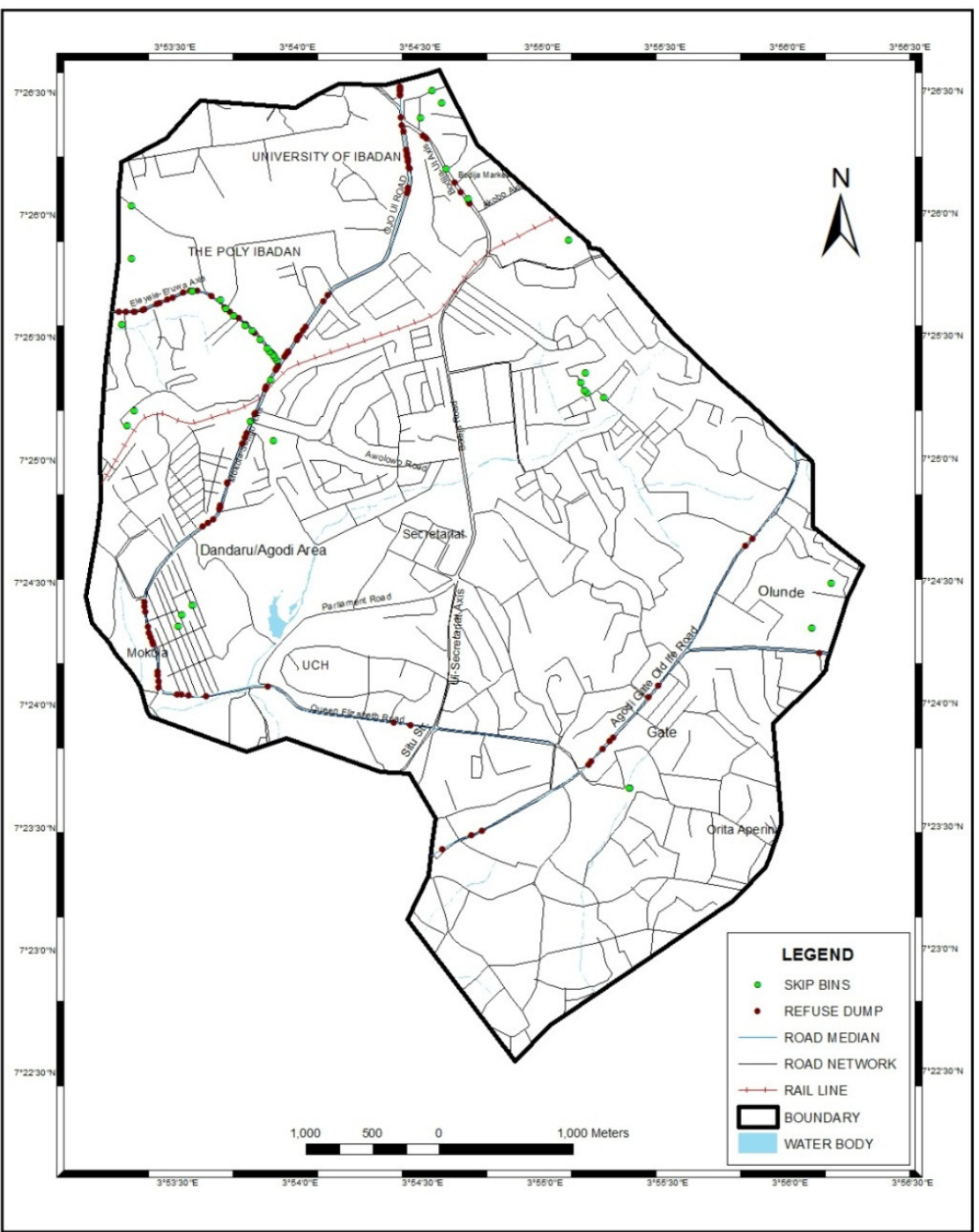

Figure 5: An overlay of Dump Points on existing road media Median within the Study Area 
Locations of the Skip bins and the points of refuse dump on medians were overlaid in figure 4. The displayed locations of skip bins and points of refuse dump on median also shows the clustered distribution of Skip bins and points of indiscriminate waste disposal respectively within Ibadan North.

\section{Effects of Indiscriminate Dumping}

The problem of indiscriminate dumping range from environmental to health and to social issues. Where skips are too far, the communities dump wastes indiscriminately and some disposal points are often overflowing with uncollected wastes. Solid waste that is left out is scattered by wind, animals, children or waste pickers. Thus, a lot of these wastes actually end up in the environment. When collection service is delayed, solid waste is not collected, causing considerable nuisance- air pollution due to bad odor. Also, flies perches on this uncollected waste and goes ahead to settle on food items contaminating them and impacting on the health of the consumers. Solid waste should be collected more often in hot climate to control fly breeding. Other factors to consider are the odors caused by decomposition and the accumulated quantities. Flooding also results from clogging of drainage channels by dumped solid wastes so also increase in road sedimentation and growth of weeds along the roads which often times damage the roads.

\section{Factors Contributing to Indiscriminate Dumping of Refuse}

Dumping of waste by the roadside or along the median is inappropriate, unhealthy and untidy, it is nonenvironmental friendly as it contributes to environmental nuisance/ disturbance- air pollution, poor sanitation defacing the environment, and likewise has health implications.

Some of the major factors that contribute to indiscriminate dumping of solidwaste along road medians and by the road side identified during the questionnaire administration include people's culture or attitude; a careless attitude permeates the thinking of many Nigerians and some people have some superstitious belief about waste generated and thus prefer to burn and dispose them into flowing river/water, distance to skip bin location is another factor, community population, nearness to market, waste collectors' route/ presence of Road Sweepers (OYWMA), poor public awareness and ignorance/ lack of education.

\section{Conclusion}

The quantity and the rate of solid wastes generation in Nigeria have outgrown the capacity of nature to naturally absorb them (Babayemi and Dauda, 2009). Consequently, the infrastructures put in place by the agencies and the attitude of the people to keeping the environment clean contributes immensely to the state of these cities. To solve the problem of indiscriminate dumping of refuse in Ibadan and in Oyo state at large, solid waste management policies in Oyo State should be energized and sanitation laws be empowered. The parameters for reprimanding anyone caught violating these laws should be also put in place so that people can desist from the act of indiscriminate dumping. Education and awareness for the citizens to put off the long-acquired habit of indiscriminate waste disposal is eminent. Public health 
educators/ Environmentalists should be mobilized to educate people on the need for proper waste disposal and this enlightenment should be done on a continuous basis so that the populace is kept reminded of their responsibilities in building a better, cleaner and healthier environment and State. Proper location of skip bins should also be ensured. It is wrong and unhealthy that skip bins are placed on roads reducing road coverage that is accessible to people and moving vehicles and in front of dwellings or commercial constructions where food items are sold. The number of skip bins should also be increased, that is, more skip bins should be made available within short distances. And likewise, the frequency of waste collection from the available and proposed skips should be on a more regular basis. It is evident that efficient city road network is needed for proper waste collection and management. Thus, for efficient waste collection, there is a need for good road network for waste managers to ply in order to collect the refuse generated.

\section{Recommendations}

Based on the problem of median dumping of refuse identified, there is a need for a quick planning response to be provided to prevent the emergence of ugly city and ugly outlook in the study area. This study proposes the Sustainable Waste Management Approach of 4Rs which include Waste Reduction (identify waste minimization opportunities and be committed to action), Waste Re-use (in form of the use of waste for compost) and Waste Recycle (production of useful materials from waste garbage) and Waste Recovery. The other proposed approach is the redesigning of the location of the waste infrastructure (waste bin). The planning standard for the location of waste facilities was applied following the Federal Ministry of Environment (FME, 2005) policy guideline on waste management in Nigeria since none is stipulated in the handbook for Space Standard for physical Development in Oyo State. It was observed in practice that the location of skip bin differ greatly from one place to the other in terms of thresholds and catchments; space standards; numbers of users at any one time; and distribution of use through the day and through the week, hence, it is proposed that sites should primarily be chosen for convenience of access to their catchment area in terms of potential users. Small containers can be placed on sidewalks, whereas larger skips require larger sites. FME (2005) proposed that for communal waste storage disposal facility, a 200-250m walking distance should be observed between the locations of one facility to another. The FME policy guideline maintained that detailed information regarding utility performance standards, threshold and nature of activity can act as benchmarks to check the accessibility of utility locations. For these utility points, which are accessed primarily by pedestrians, it assume an average walking speed of $50 \mathrm{~m} / \mathrm{min}$ which denotes a walking distance and time of $200 \mathrm{~m}$ and four minutes respectively. Also, the space density (population density, residential density and building density), nature of activity (commercial and residential), rate of waste generation (average of half a day and a full day for a skip bin to get filled), waste collection (average of a day and half), income of community (High, and low income earners) were used as the basis for the proposal.

Hence, 38 additional skip bins were proposed for the study area as shown in fig. 5 and these skip bins are systematically distributed within the study area following 
the FME standard of a distance of 200$250 \mathrm{~m}$ between waste infrastructure so as to cushion the effect of indiscriminate waste disposal. 2 were proposed at sango, 2 along eleyele axis, 1 around the University of Ibadan, 1 at Agbowo, 3 at Bodija, Ashi axis, 3 at Bodija Estate, 1 at Olaogun, 6 at Bere, Oje Axis, 1 along Parliament road, 1 along Queen Elizabeth road, 1 at OkeAdo,3 at OritaAperin, 1 at Dandaru Area, 1 at Gate, 2 at Ikolaba, 1 along Akede street, 1 along Orelere Street, 1 along Oyelese Street, 1 alongIdowu Street, 3 at Agodi and 2 along the State Secretariat road. Figure 5 shows the proposed facility location).

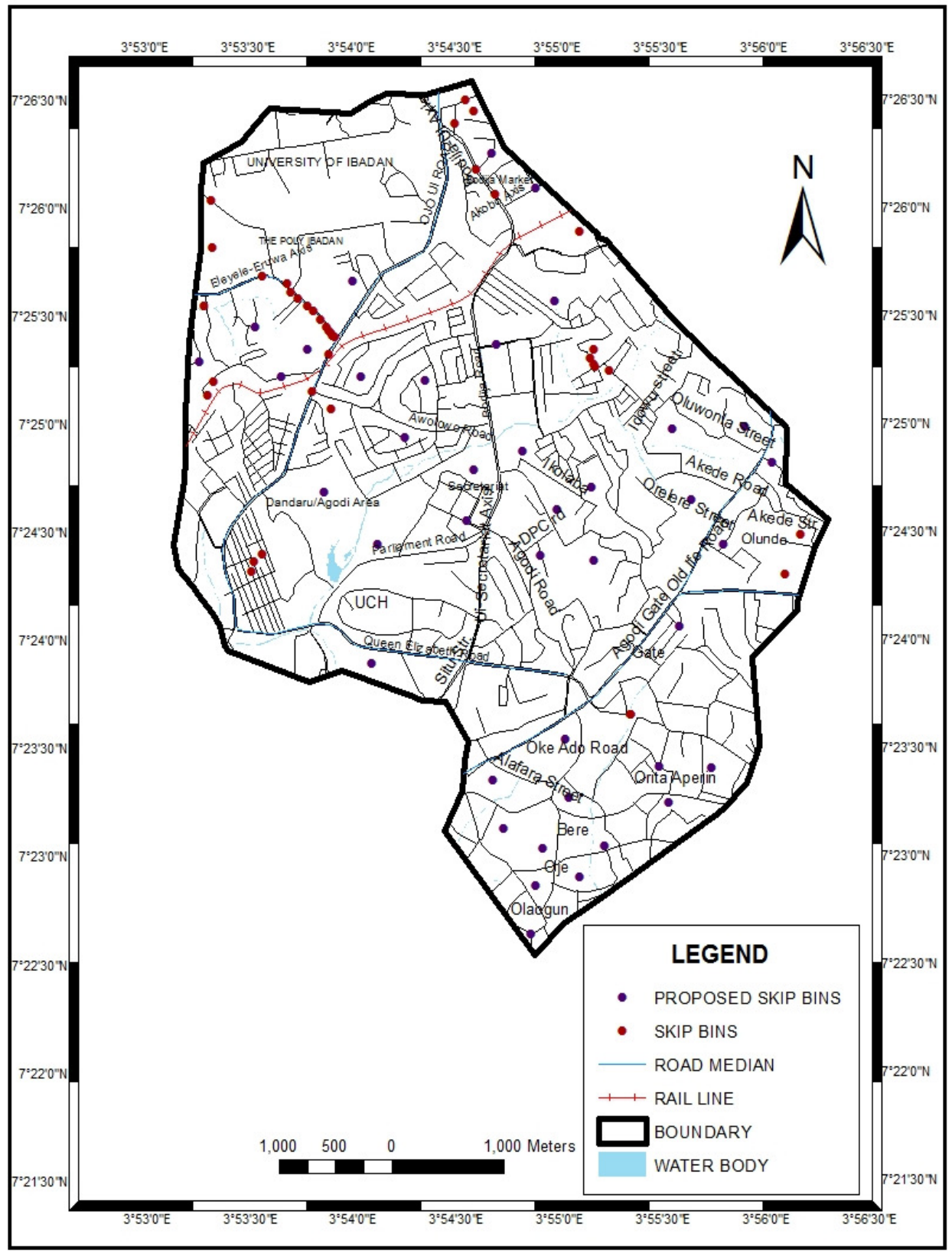

Figure 6: Proposed skip bins within the Study Area. 
Assessment of Solid Waste Management Systems in Ibadan North...............POPOOLA et al.

\section{References}

Adejobi, O. S. and Olorunnimbe, R. O. (2012). Challenges Of Waste Management And Climate Change In Nigeria: Lagos State Metropolis Experience. African J. Sci. Res. 7(1): 346-362.

Amuda, O.S., Adebisi, S.A., Jimoda L.A., and Alade, A.O. (2014). Challenges and Possible Panacea to The Municipal Solid Wastes Management In Nigeria. Journal of Sustainable Development Studies, 6(1): 64-70. Issn 2201-4268.

Babayemi, J.O. and Dauda, K.T. (2009). Evaluation of Solid Waste Generation, Categories and Disposal Options in Developing Countries: A Case Study of Nigeria. J. Appl. Sci. Environ. Manage., 13(3): $83-88$

Federal Ministry of Environment (FME), (2005). Environmental Health Watch: Policy Guideline on Solid Waste Management.

GISC. (Geographic Information System Collective). (2014). Average Nearest Neighbour. www.giscollective.org/tutorials/gis Accessed 24-10-14

Mundhe, N., Jaybhaye, R. and Dorik, B. (2014). Assessment of Municipal Solid Waste Management of Pune City using Geospatial Tools. International Journal of Computer Applications, 100(10): 0975 8887).
NIPOST.2009.Post Offices- with map of LGA".NIPOST.Retrieved 2009-1020.

Ogwuche, J.A. (2013). Spatial location of Solid Waste dumpsites and collection scheduling using the Geographic Information Systems in Bauchi metropolis, Nigeria. European Scientific Journal, 9(11): ISSN: 1857 - 7881 (Print) e - ISSN 1857- 7431374

Onu, B., Price, T., Surendran, S.S. and Ebie, S. (2012). Solid Waste Management: A Critique of Nigeria's Waste Management Policy

Schwarz-Herion, O., Omrana. and Rapp, H.P. (2008). A Case Study on Successful Municipal Solid Waste Management in Industrialized Countries By The Example Of Karlsruhe City, Germany. J. Eng. Annals. 6(3): 266-273.

Shah, S.A. and Wani, M.A. (2014). Geospatial Based Approach for enhancing Environment Sustainability of Srinagar city - A Study on Solid Waste Disposal. International Journal of $u$ - and $e$ Service, Science and Technology. 7(3): 289-302. http://dx.doi.org/10.14257/ijunesst. 2014.7.3.25.ISSN: 2005-4246 IJUNESST Copyright (C) 2014 SERSC 